\title{
A globalização da penalidade neoliberal? Comentários sobre a conexão EUA, França e Brasil proposta por Loïc Wacquant
}

\author{
Letícia Figueira Moutinho Kulaitis ${ }^{1}$
}

\begin{abstract}
Resumo: O presente artigo abrange uma análise da tese de Loïc Wacquant de que a partir da hegemonia ideológica dos Estados Unidos da América estabelece-se a adoção na Europa e na América Latina, em especial no Brasil, de uma penalidade neoliberal. Para Wacquant, seguindo o modelo norte-americano, países como a França e o Brasil tem orientado suas políticas no sentido da adesão de um "mais Estado policial/penitenciário" e de um "menos Estado econômico e social", assumindo, desse modo, a ideologia norte-americana do mercado total. O resultado, em termos objetivos, é o aumento significativo do encarceramento de jovens, pobres e negros, nos países analisados por Wacquant, exprimindo, portanto, um tratamento penal da miséria. O objetivo deste artigo é compreender de que modo a penalidade neoliberal emerge como uma nova faceta do processo de globalização. Para tanto são analisados os textos produzidos por Loïc Wacquant que tratam do tema em questão bem como de outros autores que contribuem para a discussão do tema. São analisados dados empíricos sobre o total de indivíduos encarcerados e o perfil destes por meio das estatísticas produzidas pelo Ministério da Justiça no Brasil e órgãos correlatos nos Estados Unidos e França.
\end{abstract}

Palavras-chave: Estado Penal, Neoliberalismo e Globalização.

\section{The globalization of neoliberal penality? Comments on the US, France and Brazil connection proposed by Loïc Wacquant}

\begin{abstract}
This article covers an analysis of Loïc Wacquant's thesis that from the ideological hegemony of the United States of America the adoption in Europe and Latin America, especially in Brazil, of a neoliberal penalty is established. According to Wacquant, following the American model, countries such as France and Brazil have oriented their policies towards a "more police / penitentiary state" and a "less economic and social state" the American ideology of the total market. The result, in objective terms, is the significant increase in the imprisonment of young people, poor and black, in the countries analyzed by Wacquant, thus expressing a criminal treatment of misery. The objective of this article is to understand how the neoliberal penalty emerges as a new facet of the globalization process. For that, we analyze the texts produced by Loïc Wacquant that deal with the topic in question as well as other authors who contribute to the discussion of the theme. Empirical data on the total number of incarcerated individuals and their profile are analyzed through statistics produced by the Ministry of Justice in Brazil and related bodies in the United States and France.
\end{abstract}

\footnotetext{
${ }^{1}$ Doutora em Sociologia pelo Programa de Pós-Graduação em Sociologia da Universidade Federal do Paraná (2016). E-mail: leticia.kulaitis@gmail.com.
} 
Revista NEP, Núcleo de Estudos Paranaenses, Curitiba, v.4, n.2, dez. 2018

Key words: Criminal State, Neoliberalism and Globalization.

\section{Sobre a penalidade neoliberal}

O fenômeno da globalização tem sido analisado por múltiplas perspectivas e seu impacto nas formações sociais é objeto de debate corrente no campo da Sociologia. No entanto, para além das relações econômicas, políticas e culturais, identifica-se também o impacto do processo de globalização nas práticas de controle da violência e da criminalidade.

A experiência da violência, seja por meio dos conflitos internos ou externos, é compartilhada por diferentes países. Embora seja um fenômeno constante nas formações sociais, altas taxas de crime e, portanto, de violência, levam a busca de soluções que atendem à demanda dos indivíduos por segurança.

O que nos interessa no presente artigo é o processo de internacionalização, como proposto por Loïc Wacquant ${ }^{2}$, de um novo senso comum penal, idealizado pelos Estados Unidos, cuja característica essencial é a criminalização da miséria e a normatização do trabalho assalariado precário.

$\mathrm{Na}$ perspectiva adotada por Wacquant, a partir da hegemonia ideológica dos Estados Unidos estabelece-se a adoção na Europa e na América Latina de uma penalidade ${ }^{3}$ neoliberal. Segundo essa perspectiva, as noções que tem orientado o controle da criminalidade na Europa e na América Latina são constituídas a partir de termos e teses provenientes dos Estados Unidos.

Para Wacquant, seguindo o modelo norte-americano, países como a França e o Brasil tem orientado sua política no sentido da adesão de um mais Estado policial/penitenciário e de um menos Estado econômico/social, assumindo, desse modo, a ideologia norte-americana do mercado total (WACQUANT, 2001, p.7).

\footnotetext{
2 O tema da criminalização da miséria tem sido discutido por Wacquant em diferentes obras e artigos desde os anos 2000. Destacam-se, nesse conjunto, as obras As prisões da miséria (2001), Os condenados da cidade: estudo sobre marginalidade avançada (2001a) e Punir os pobres: a nova gestão da miséria nos Estados Unidos (2007).

${ }^{3}$ Como esclarece nota do tradutor André Telles, "o termo penalidade refere-se ao conjunto de práticas, instituições e discursos relacionados à pena e, sobretudo, à pena criminal” (WACQUANT, 2001, p. 7).
} 
Revista NEP, Núcleo de Estudos Paranaenses, Curitiba, v.4, n.2, dez. 2018

A expressão neoliberal, associada por Wacquant a atividade penal, refere-se a doutrina político-econômica, adotada por diferentes países nos anos 1990, que defende a regulação da intervenção do Estado na economia ${ }^{4}$. A existência de um livre mercado garantiria o crescimento econômico e o desenvolvimento social de um país. São princípios da doutrina neoliberal: a desregulação econômica, a retração das políticas de bem-estar social, o surgimento ou expansão de um aparelho penal de grandes dimensões e a cultura da responsabilidade individual.

O desenvolvimento do neoliberalismo implicou em reforço das exigências de trabalho, benefícios de bem-estar social limitados, e redução da disponibilidade desses benefícios. Tal desenvolvimento foi acompanhado da exacerbação do Estado Penal como meio de conter as consequências do enfraquecimento do Estado de bem-estar social. Campbell aponta que como oportunidades de trabalho e de apoio social secaram, o crime tornou-se uma alternativa mais tentadora, o que levou à subida das taxas de encarceramento e à uma expansão do Estado penal (CAMPBELL, 2010, p. 60) ${ }^{5}$.

Sobre a ausência de uma rede de proteção social que Wacquant sinaliza que:

o trabalho assalariado desregulamentado - que alguns insistem em apresentar como uma espécie de necessidade natural (também importada dos Estados Unidos), filha de uma 'globalização' inelutável, embora nem sempre desejável - e o recurso crescente ao braço policial e penitenciário do Estado para abafar as desordens sociais e mentais, engendradas pela instabilidade do trabalho não são uma fatalidade. (WACQUANT, 2007, p. 467).

Materializa-se, portanto, a substituição de um Estado-providência "materialista" por um Estado punitivo "paternalista" que objetiva impor o trabalho assalariado como uma obrigação de cidadania (WACQUANT, 2001, p. 44). As questões sociais, como a miséria, o desemprego, a ociosidade, são, neste contexto, percebidos como questões individuais, atribuídas a responsabilização individual e garante-se, nesse momento, que

\footnotetext{
4 "Minha tese central de que o rápido crescimento e a exaltação da polícia, dos tribunais e das prisões nas sociedades do Primeiro e do Segundo Mundo nas duas últimas décadas são um elemento essencial da revolução neoliberal" (WACQUANT, 2012, p. 13).

5 Tradução livre.
} 
Revista NEP, Núcleo de Estudos Paranaenses, Curitiba, v.4, n.2, dez. 2018

aqueles que não se adaptem as exigências do mercado possam encontrar a prisão como destino.

Campbell critica a relação estabelecida, por Wacquant, entre o neoliberalismo e o recrudescimento da atividade penal. Para Campbell (2010, p. 62), a análise de Wacquant é fortemente estruturalista, apresentando o sistema penal como um elemento funcionalmente necessário para a ascensão do neoliberalismo. Essa associação não caberia a observação, feita por Wacquant, de que as taxas de encarceramento são muito mais baixas em países avançados, a exceção dos Estados Unidos.

O autor sugere que a análise de Wacquant ignora a dimensão política na formação da penalidade neoliberal bem como não contempla a possibilidade de que Estados reconhecidos como neoliberais não caminhem em direção a adoção de um Estado penal superdimensionado e que em outros, essa tendência possa ser revertida. Campbell sugere, por fim, que esta tendência pode ser, de fato, restrita aos Estados Unidos, e sendo assim, Wacquant teria generalizado um fenômeno particular (CAMPBELL, 2010, p. 70).

Para compreender de que modo Wacquant busca articular o fenômeno do recrudescimento penal nos Estados Unidos e seus ecos na Europa, em especial na França, e na América Latina, em especial no Brasil, é necessário situar de que modo o autor percebe a conexão estabelecida entre esses países.

A difusão do modelo de penalidade adotado pelos Estados Unidos foi sustentada pelo aparente sucesso das políticas de controle da criminalidade adotadas pela cidade de Nova Iorque. Estas políticas, por sua vez, tinham por base a chamada teoria das "janelas quebradas" (broken windows theory), concebida pelo Manhattan Institute ${ }^{6}$, segundo a qual a solução para o combate ao crime está no controle/repressão dos pequenos distúrbios cotidianos e na realização de melhorias no espaço urbano.

\footnotetext{
${ }^{6}$ Criado, em 1978, na cidade de Nova Iorque, o Manhattan Institute tem grande influência na formação da cultura política americana. $\mathrm{O}$ instituto, por meio da realização e divulgação de pesquisas, procura influenciar a formulação de políticas públicas em diferentes áreas. Em seu portal na internet, o Instituto é definido como é um think tank, cuja missão é desenvolver e disseminar novas idéias que promovem uma maior escolha econômica e responsabilidade individual (2012).
} 
Revista NEP, Núcleo de Estudos Paranaenses, Curitiba, v.4, n.2, dez. 2018

A teoria das "janelas quebradas" repercutiu, no caso do Brasil, em diferentes políticas de urbanização em áreas marginalizadas em grandes cidades ${ }^{7}$. Perpassa essas políticas a concepção de que a recuperação de áreas urbanas tem reflexo no controle da criminalidade.

A política de Tolerância Zero adotada pela prefeitura de Nova Iorque foi responsável pela redução dos serviços sociais e ampliação da aplicação rigorosa da lei sobre delitos de menor potencial ofensivo (embriaguez, jogatina, pequenos furtos, mendicância, não pagamento de transporte, prostituição, atentados aos costumes, simples ameaças). O sucesso da política foi divulgado pelo mundo como solução para o controle da criminalidade ${ }^{8}$. No entanto, de acordo com Wacquant (2001. p. 29), a queda da criminalidade em Nova York, é associada de forma prematura à política de tolerância zero.

A política é retransmitida como um programa ideológico a ser adotado por diferentes países:

E, com ela, a retórica militar da 'guerra' ao crime e da 'reconquista' do espaço público, que assimila os delinquentes (reais ou imaginários), sem-teto, mendigos e outros marginais a 'invasores estrangeiros' - o que facilita o amálgama com a imigração, sempre rendoso eleitoralmente. (WACQUANT, 2001, p. 30).

A aplicação da política de tolerância zero, nos Estados Unidos, resultou na detenção e revista de um número elevado de indivíduos, com base em seu vestuário, aparência, comportamento e cor da pele. As detenções eram, em sua maioria,

\footnotetext{
${ }^{7}$ Um exemplo recente é o projeto Espaços Urbanos Seguros, ação integrante do Programa Nacional de Segurança Pública com Cidadania - PRONASCI, do Ministério da Justiça. Na ação, proposta em parceria com Estados e municípios, os espaços urbanos seguros são definidos como "ambientes públicos planejados, projetados e administrados de forma participativa com vistas a reduzir incidência de delitos e da violência, aumentar a sensação de segurança das pessoas que o utilizam, bem como a sua permanência no local e a apropriação da comunidade para atividades de convivência, melhorando, assim, a qualidade de vida da população" (MINISTÉRIO DA JUSTIÇA, 2009, p.1).

${ }^{8}$ No Brasil, “em janeiro de 1999, depois da visita de dois altos funcionários da polícia de Nova York, o governador de Brasília, Joaquim Roriz, anuncia a aplicação da ‘tolerância zero' mediante contratação imediata de 800 policiais civis e militares suplementares, em resposta a uma de crimes de sangue do tipo que a capital brasileira conhece periodicamente" (WACQUANT, 2001, p. 33).
} 
Revista NEP, Núcleo de Estudos Paranaenses, Curitiba, v.4, n.2, dez. 2018

consideradas injustificáveis pelos promotores de justiça e ocasionavam a sobrecarga de tribunais e instituições penitenciárias (WACQUANT, 2001, p. 35).

Trata-se, na análise feita pelo autor, de uma estratégia política segundo a qual:

fazer da luta contra a delinquência de rua um espetáculo moral permite aos atuais governantes (como também aqueles que os antecederam) reafirmar simbolicamente a autoridade do Estado no exato momento em que eles declararam sua impotência na frente econômica e social. (WACQUANT, 2007, p. 454).

A prisão é tomada, nesse contexto, como um mecanismo que torna invisível, ou menos visível, as transformações econômicas relacionadas ao processo de globalização e a adoção da via neoliberal. Ela permite que se retire do corpo da sociedade aquele que estão fora do mercado (delinquentes, desempregados, sem-teto, imigrantes sem documentação, toxicômanos e até mesmo deficientes e doentes mentais) e cuja existência depende da vinculação a rede de proteção social (WACQUANT, 2007, p. 455).

Tal argumento é reforçado pela observação de Campbell de que embora não tenha sido construído com esta intenção, o sistema penitenciário, nos Estados Unidos, colabora, de modo evidente, para a redução das taxas de desemprego neste país (CAMPBELL, 2010. p. 61).

Para Wacquant, o aumento da taxa de encarceramento não está relacionado ao aumento da taxa de criminalidade mas sim a uma forma específica de controle social. Esse é o primeiro motivo que identifica para denominar o recrudescimento do encarceramento na França de aberração carcerária. É curioso observar que o aumento do número de indivíduos encarcerados, não se relaciona com a taxa de criminalidade e também não contribui, de acordo com Wacquant (2007, p. 457), para sua diminuição.

Nesse contexto, atendendo aos seus interesses econômicos, a privatização dos estabelecimentos prisionais ganha respaldo entre significativa parcela da sociedade norteamericana9 ${ }^{9}$ A privatização de presídios, negócio reconhecidamente lucrativo nos Estados

\footnotetext{
9 Sobre a discussão da privatização de instituições penitenciárias no Brasil, Lemgruber afirma que "a privatização é inaceitável sobretudo do ponto de vista ético e moral. Numa sociedade democrática, a privação da liberdade é a maior demonstração de poder do Estado sobre seus cidadãos e, como tal, só deve ser exercida pelo próprio Estado" (LEMGRUBER, 2001, p. 16).
} 
Revista NEP, Núcleo de Estudos Paranaenses, Curitiba, v.4, n.2, dez. 2018

Unidos, é um fenômeno que perpassa, na análise de Campbell, todas as camadas da sociedade: por um lado, pune a classe 'mais baixa', que preenche as prisões, por outro lado, beneficia a classe 'alta', sua proprietária, e emprega a classe média, que a dirige (CAMPBELL, 2010, p. 61) ${ }^{10}$.

Sobre o estado atual das instituições carcerárias, Wacquant alerta que:

\begin{abstract}
Instituição baseada na força e operando à margem da legalidade (malgrado as recomendações reiteradas por muitas comissões oficiais, os detentos franceses nem sempre dispõem de um estatuto jurídico definido) a prisão é um cadinho de violências e de humilhações diárias, um vetor de desagregação familiar, de desconfiança cívica e de alienação individual $\mathrm{E}$, para muitos detentos marginalmente implicados em atividades ilícitas, é uma escola de formação, e até mesmo de 'profissionalização', na carreira do crime. (WACQUANT, 2007, p. 454).
\end{abstract}

Longe de cumprir sua missão de reintegração social, a prisão, conforme apresentada pelo autor, reforça a condição de marginalidade em que se encontra o indivíduo encarcerado.

\title{
2. A criminalização da miséria: EUA, França e Brasil
}

No ano 2000, 8.6 milhões de indivíduos encontravam-se em instituições penitenciárias em todo o mundo, dez anos depois, esse número aumento para 10.1 milhões de indivíduos encarcerados (WASLEY, 2000, 2010). Cabe destacar que metade desses indivíduos se encontravam nos Estados Unidos, Rússia ou China. Atualmente os Estados Unidos possui a maior taxa de população prisional do mundo. São 730 indivíduos presos a cada 100 mil habitantes (ICPS, 2012).

Segundo Wacquant, nos Estados Unidos, a "triplicação da população penitenciária em 15 anos é um fenômeno sem precedentes nem comparação em qualquer sociedade democrática, ainda mais por ter se operado durante um período em que a criminalidade permanecia globalmente constante e depois em queda" (WACQUANT, 2001, p. 81).

\footnotetext{
10 Tradução livre.
} 
Revista NEP, Núcleo de Estudos Paranaenses, Curitiba, v.4, n.2, dez. 2018

Mais interessante do que avaliar os números de indivíduos encarcerados nos Estados Unidos é avaliar quem são os indivíduos que se encontram nesta situação. Ou seja, qual a parcela da população que foi diretamente atingida pelo desenvolvimento da atividade penal no país. Sobre essa questão, Wacquant observa que:

\begin{abstract}
Contrariamente ao discurso político e midiático dominante, as prisões americanas estão repletas não de criminosos perigosos e violentos, mas de vulgares condenados pelo direito comum por negócios com drogas, furto, roubo, ou simples atentados à ordem pública, em geral oriundo das parcelas precarizadas da classe trabalhadora e, sobretudo, das famílias do subproletariado de cor das cidades atingidas diretamente pela transformação conjunta do trabalho assalariado e da proteção social (WACQUANT, 2001, p. $85)$.
\end{abstract}

Wacquant (2001) discute, no caso norte-americano, o peso financeiro do encarceramento em massa como política de "luta contra a pobreza" bem como a questão do aumento contínuo e envelhecimento da população carcerária. O autor aponta que no Estado da Califórnia, o custo anual de cada prisioneiro é de 22.000 dólares. Para diminuição dos custos, o Estado tem adotado medidas de corte nos recursos, que já são escassos, destinados a ensino, esporte, entretenimento e projetos de reinserção nos estabelecimentos penitenciários e tem transferido os custos da carceragem para os presos e suas famílias (WACQUANT, 2001, p. 89).

A introdução de trabalho desqualificado, com baixa-remuneração e potencial formativo, em massa no interior dos presídios também é uma estratégia norte-americana para diminuição dos impactos do custo carcerário no país ${ }^{11}$.

A análise do que Wacquant (2001) denomina de política estatal de criminalização das consequências da miséria aponta que, nos Estados Unidos, os serviços sociais vão sendo transformados em instrumentos de vigilância e controle das novas "classes perigosas", em especial da juventude ${ }^{12}$. Por fim, a prisão estabelece-se uma espécie de

\footnotetext{
${ }^{11}$ No Brasil, o projeto Pintando a Liberdade, do Ministério do Esporte, incentiva a instalação de fábricas de materiais esportivos no interior dos estabelecimentos prisionais. De acordo com o Ministério do Esporte, ao participar da iniciativa "além da profissionalização, os detentos reduzem um dia da pena para cada três dias trabalhados e recebem salário de acordo com a produção" (MINISTÉRIO DO ESPORTE, 2012). É necessário analisar, com mais vagar, o projeto para fins de comparação com as iniciativas norte-americanas.

${ }^{12}$ Hallsworth e Lea destacam a contribuição de Wacquant para a discussão da importância relativa do sistema penal em relação a um espectro de outras agências, públicas e privadas, através da qual novos
} 
Revista NEP, Núcleo de Estudos Paranaenses, Curitiba, v.4, n.2, dez. 2018

continuum destino da população negra e jovem proveniente dos guetos. Constitui-se o que o autor identifica como ditadura sobre os pobres caracterizada pela deslegitimação das instituições legais e judiciárias; a escalada da criminalidade violenta, dos abusos policiais (dirigidos a população jovem, negra e pobre), a criminalização dos pobres, a utilização de práticas ilegais de repressão, a obstrução generalizada ao princípio da legalidade e a distribuição desigual e não equitativa dos direitos de cidadania.

As consequências das políticas neoliberais - precariedade e pobreza de massa, insegurança social, desigualdade social, segregação, criminalidade e abandono das instituições públicas - são tratadas, no processo de criminalização da miséria, como questões individuais, relacionadas à questões morais. Como resposta a decadência econômica e a segregação social, aponta-se para o endurecimento da intervenção penal. Para Wacquant, “à violência da exclusão econômica, ele [o Estado] oporá a violência da exclusão carcerária” (WACQUANT, 2001, p. 74).

O objetivo do senso penal, difundido a partir do modelo norte-americano:

não é mais nem prevenir o crime, nem tratar os delinquentes visando o seu eventual retorno à sociedade uma vez sua pena cumprida, mas isolar grupos considerar perigosos e neutralizar seus membros mais disruptivos mediante uma série padronizada de comportamentos e uma gestão aleatória dos riscos, que se parecem mais com uma investigação operacional ou reciclagem de ‘detritos sociais' que com trabalho social .(WACQUANT, 2001, p. 87).

Na perspectiva apresentada por Wacquant, a sociedade brasileira caracteriza-se por grandes disparidades sociais, pela pobreza e pelo crescimento alarmante da violência criminal. Este contexto está diretamente associado às representações sociais da juventude pois:

na ausência de qualquer rede de proteção social, é certo que a juventude dos bairros populares esmagados pelo peso do desemprego e do subemprego crônicos continuará a buscar no 'capitalismo de pilhagem' da rua (como diria Max Weber), os meios de sobreviver e realizar os valores do código de honra masculino, já que não consegue escapar da miséria do cotidiano. (WACQUANT, 2001, p.8).

mecanismos de controle do estado neoliberal estão sendo estabelecidos (HALLSWORTH; LEA, 2012, p. 193). 
Revista NEP, Núcleo de Estudos Paranaenses, Curitiba, v.4, n.2, dez. 2018

A propagação do crime e do medo do crime ocorrem, no país, de acordo com Wacquant $(2001$, p. 8) por conta da difusão das armas de fogo, o desenvolvimento de uma economia estruturada da droga ligada ao tráfico internacional e a mistura entre o crime organizado e a polícia.

A entrada do jovem no mundo da criminalidade necessita ser analisada, à luz da teoria sociológica, não como uma opção pessoal, reduzida, portanto à esfera individual, mas como uma expressão da dinâmica estabelecida entre o indivíduo e a sociedade na qual se insere. A certos tipos de indivíduos são imputadas certas classes de comportamento e dentro do processo de criminalização da marginalidade, são consideradas elevadas as probabilidades de que a atividade criminosa venha a ser realizada pelo tipo de indivíduo socialmente marginalizado (COELHO, 2005, p. 284).

Este processo torna-se ainda mais eficaz quando a associação entre marginalidade social e criminalidade é:

recoberta com o verniz da erudição dos técnicos e especialistas (sobretudo dos que trabalham em agências governamentais, já que normalmente têm menos liberdade para divergir das concepções oficiais), ficam justificados e legitimados programas públicos de redução da marginalização social, os quais, no geral e nesse contexto de justificação, agravam o estigma da pobreza. (COELHO, 2005, p.287).

Dada a complexidade da questão da criminalidade e da violência no Brasil, tornase de difícil apreensão a relação de conexão entre a penalidade neoliberal, representada pelo modelo norte-americano, e o Sistema de Justiça Criminal, ou seja, da atividade penal. Se faz necessária, a discussão, para além do que propõe Wacquant (2001) das especificidades do caso brasileiro, como por exemplo, da fragilidade, no país, das políticas de bem-estar social e das condições dos estabelecimentos penais, ainda mais precárias do que as apontadas pelo autor, no caso norte-americano e ou europeu.

Nesse sentido, Lemgruber ressalta que, no Brasil:

a escassez de informações não só sobre o que ocorre no próprio país, mas também sobre experiências internacionais deixa espaço para a reprodução de crenças e mitos que há muito já vem sendo questionados em outras partes do mundo - como, por exemplo, a eficácia da pena de morte, os benefícios do 
Revista NEP, Núcleo de Estudos Paranaenses, Curitiba, v.4, n.2, dez. 2018

'endurecimento penal', as vantagens da privatização de prisões e os efeitos dissuasivos da pena privativa de liberdade (LEMGRUBER, 2001, p. 1)

A autora destaca ainda que a ausência de estudos que comparem as curvas de criminalidade e de encarceramento no Brasil impede que se estabeleça uma relação entre o aumento de crimes e o aumento da população carcerária (LEMMGRUBER, 2001, p. $8)$.

Sem dúvida, como Wacquant aponta, caminhamos, no Brasil, para um encarceramento em massa da população jovem, negra e miserável, como apontam os perfis estatísticos dos apenados ${ }^{13}$. É interessante observar que o crescimento da população carcerária tem sido mantido contínuo: entre 2000 e 2016, o aumento foi de aproximadamente 208\%, o número de encarcerados passou de 232.755, em 2000, para 726.712, em 2016 (DEPEN,2017).

O déficit de vagas no Sistema Penitenciário tem motivado frequente debate sobre a necessidade de investimento, por parte do Estado, na construção de novos estabelecimentos penitenciários. A influência da cultura do mote norte-americano de privatização de instituições prisionais já é parte da discussão, sendo motivo de alerta por parte dos especialistas. Lemgruber aponta que "países com o Brasil, que precisam investir na redução da pobreza e das miseráveis condições de vida de parcelas tão grandes da população, não podem deixar-se iludir pelo falso fascínio das prisões privadas" (LEMGRUBER, 2001, p. 18).

A solução da criminalidade, no país, não se reduz, nesse sentido, a iniciativa de construção de estabelecimentos penais. Como alerta Lemgruber:

Se, em outros países, não se consegue demonstrar que o encarceramento é justificável em termos de custo-benefício, há muito pouco, realismo em supor que, no Brasil, a mera multiplicação de prisões e de presos, com um gigantesco aumento de gastos, poderia produzir resultados compensadores no controle da criminalidade. Mais realista é investir na diversificação das formas e recursos punitivos à disposição da Justiça, reservando a pena privativa de liberdade para

13 Dados compilados pelo Departamento Penitenciário Nacional registram que, no ano de 2016, 55\% da população carcerária é composta por jovens entre 18 e 29 anos. Na população carcerária, 53\% são negros. Neste mesmo ano, $4 \%$ da população carcerária era composta por analfabetos, $6 \%$ eram alfabetizados e $51 \%$ possuíam o ensino fundamental incompleto. Se somarmos o quantitativo, temos $61 \%$ dos encarcerados com baixíssima escolaridade (DEPEN, 2017). 
Revista NEP, Núcleo de Estudos Paranaenses, Curitiba, v.4, n.2, dez. 2018

aqueles que, efetivamente, precisam ser afastados do convívio social (LEMGRUBER, 2001, p. 24).

No caso da França, Wacquant aponta para o fenômeno que denomina de explosão programada da população carcerária e destaca que ao ultrapassar 60.000 presos, a França chega a um número recorde de presos desde o final da segunda guerra mundial (WACQUANT, 2007, p. 451).

Ao identificar a afirmação, pelo Ministério da Justiça francês, de uma explosão da delinquência juvenil, Wacquant (2001) esclarece que os dados estatísticos apontam que as infrações cometidas por jovens não aumentaram nem diminuíram e estas não se tornaram mais violentas, ou seja, a afirmação da violência urbana:

É um absurdo estatístico que mistura tudo e qualquer coisa, que o Ministério da Justiça invoca para excluir, das medidas de limitação da detenção provisória, os indivíduos detidos no contexto de comparecimentos imediatos, ou seja, a metade das prisões preventivas (40.000 a cada ano) - que, como é sabido, atingem prioritariamente os membros das classes populares e dos bairros relegados. (WACQUANT, 2001, p. 69).

A manipulação dos dados estatísticos, pelos órgãos oficiais, expressa a necessidade de justificar, ainda que forma incompreensível, o processo de criminalização da pobreza e da juventude. Sobre a política de segurança pública do Estado neoliberal, Wacquant (2001, p. 70) questiona:

quem, seriamente, pode de fato acreditar que prender algumas centenas de jovens a mais (ou a menos) mudará o que quer que seja no problema que insistem até mesmo em se recusar a nomear: o aprofundamento das desigualdades e a generalização da precariedade salarial e social sob o efeito das políticas de desregulamentação e da deserção econômica e urbana do Estado?.

Na conexão estabelecida, por Wacquant, entre a penalidade neoliberal norteamericana e a francesa, o elemento do crescimento exacerbado do sistema penitenciário, encontra menor força nos dados empíricos, se comparado ao Estados Unidos e ao Brasil. Tal afirmação se justifica pelo crescimento de aproximadamente $45 \%$ da população carcerária, na França, no intervalo compreendido entre 2000 e 2016, passando de 48.835, 
Revista NEP, Núcleo de Estudos Paranaenses, Curitiba, v.4, n.2, dez. 2018

em 2000, para 71.190 indivíduos encarcerados, em 2016. Como visto, no mesmo período no Brasil a taxa de crescimento foi de $208 \%$.

Como demonstrado na tabela baixo, os países, que ocupam lugar central na análise da obra As prisões da Miséria, apresentam uma população carcerária significativo e cujo crescimento, como demonstram a análise de suas séries históricas, tem sido contínuo.

TABELA 1 - TAXA DE ENCARCERAMENTO POR 100 MIL HABITANTES - BRASIL, EUA E FRANÇA - 2016

\begin{tabular}{c|cc}
\hline PAÍ́S & População prisional & População prisional por 100.000 habitantes \\
\hline Brasil & 726.712 & 347 \\
EUA & 2.121 .600 & 655 \\
França & 71.190 & 110 \\
\hline
\end{tabular}

FONTE: 〈www.prison.studies.org〉.

Wacquant ressalva que "na maioria dos países europeus, o aumento dos efetivos presos deveu-se à maior duração das detenções mais do que uma grande inflação das condenações à privação de liberdade, ao contrário dos Estados Unidos” (WACQUANT, 2001, p. 102). Segundo o autor, aplica-se a França a observação sobre o aumento na duração das penas aplicadas.

No entanto, destaca-se, no exemplo francês, a associação de um tratamento social e um tratamento penal das consequências, já citadas neste artigo, da adoção da doutrina neoliberal. Como indica o autor:

A tentação de se apoiar nas instituições judiciárias e penintenciárias para eliminar os efeitos da insegurança social engendrada pela imposição do trabalho assalariado precário e pelo retraimento correlato da proteção social também se faz sentir em toda a parte na Europa, e peculiarmente na França, à medida que aí se manifestam a ideologia neoliberal e as políticas por ela inspiradas, tanto em matéria de trabalho como de justiça. (WACQUANT, 2001, p. 102).

Nos países estudados, o autor observa a "reengenharia do Estado para promover as condições econômicas e socio morais que se aglutinam sob o neoliberalismo hegemônico e que buscam responder a elas" (WACQUANT, 2012, p.9). Percebe-se, 
Revista NEP, Núcleo de Estudos Paranaenses, Curitiba, v.4, n.2, dez. 2018

portanto, na conexão proposta por Wacquant, o reforço do papel do Estado de organização coletiva da violência, de manutenção da ordem estabelecida e submissão dos dominados.

\title{
3. A atualidade do modelo proposto por Wacquant
}

Em artigo intitulado A tempestade global da lei e da ordem, Wacquant (2012) revê o modelo construído por ele sobre a relação entre o neoliberalismo e a penalidade punitiva. Segundo o autor:

\begin{abstract}
a tempestade global da lei e da ordem estendeu-se dos países do Primeiro Mundo para os do Segundo Mundo e alterou a política e as práticas de punição em todo o globo de uma forma que ninguém previa e que ninguém teria pensado como possível há cerca de 15 anos. (WACQUANT, 2012, p. 7).
\end{abstract}

O artigo, publicado em 2012, propõe uma reflexão sobre a repercussão ${ }^{14}$ da obra As prisões da Miséria. Sobre a obra, o autor esclarece que seu:

\begin{abstract}
argumento central estabelece um elo entre a reestruturação neoliberal e a punição: o 'Consenso de Washington' sobre a desregulamentação econômica e a retração do Estado do bem-estar foi ampliado para abranger o controle do crime punitivo porque a 'mão invisível' do mercado necessita do "punho de ferro" do Estado penal e convoca-o. (WACQUANT, 2012, p. 8).
\end{abstract}

Motivado pelo crescimento excepcional do aparato de Justiça Criminal no gueto negro nos Estados Unidos e de sua agressividade, Wacquant escreve As prisões da Miséria, evidenciando em sua obra a substituição nos Estados Unidos e na Europa do bem-estar social pela gestão penal da marginalidade urbana.

A reflexão do autor sobre a obra o leva a compreensão de que o fenômeno da penalidade neoliberal, espalhou-se, a partir dos Estados Unidos, não só pela Europa como também pela América Latina. Observando a realidade política em diferentes partes do globo, Wacquant constata que:

\footnotetext{
${ }^{14}$ A obra intitulada Les Prisons de la misère publicada na França em 1999, foi traduzida e republicada em mais de 12 idiomas em apenas poucos anos após sua publicação original. $\mathrm{O}$ autor foi convocado, após a divulgação da publicação, por universidades, organizações profissionais, políticas e governamentais a debater sua obra e proferir palestras em diferentes locais do mundo sobre o modelo que havia proposto.
} 
Revista NEP, Núcleo de Estudos Paranaenses, Curitiba, v.4, n.2, dez. 2018

\begin{abstract}
Embora eu tivesse mirado com minha análise o cerne da União Europeia, o modelo do vínculo entre neoliberalismo e tratamento punitivo da insegurança nele esboçado era ainda mais pertinente à periferia do Velho Mundo, apanhada nos estertores da conversão pós-soviética e aos países do Segundo Mundo marcados por uma história de autoritarismo, uma concepção hierárquica da cidadania e pobreza em massa, sustentada por desigualdades sociais excessivas e crescentes, nas quais a punição da pobreza certamente terá consequências calamitosas. (WACQUANT, 2012, p, 11).
\end{abstract}

Para o autor, o debate sobre a penalidade neoliberal, ou em outros termos, sobre a criminalização da miséria nos países que adotaram a doutrina neoliberal mantêm-se atual e é necessário examinar com minúcia os processos de seleção e tradução de noções e medidas penais que passam despercebidos na análise dos Sistemas Jurídicos (WACQUANT, 2012, p. 16).

Tal esforço analítico é fundamental para a compreensão da conexão estabelecida, por Wacquant, entre o Sistema de Justiça Criminal norte-americano, francês e brasileiro.

\title{
4. Considerações finais
}

O presente artigo propôs-se a analisar, a partir da obra As prisões da Miséria (2001) de Loïc Wacquant, a conexão estabelecida pelo autor entre o desenvolvimento da doutrina neoliberal e o recrudescimento do Estado Penal.

Wacquant aponta que, na França e no Brasil, a doutrina norte-americana encontra o interesse e a anuência das autoridades dos países destinatários (WACQUANT, 2001, p. 52) e o encarceramento, ainda que sujeito à adaptações às tradições políticas e intelectuais nacionais, é adotado como uma solução para a criminalidade e para as consequências sociais postas pela desregulação econômica.

Trata-se, portanto, para além de um projeto político, de uma escolha acerca do tipo civilização que se pretende: que caminhe para o fortalecimento do Estado penal ou para a reconstrução efetiva das capacidades sociais do Estado.

Nesse sentido, o debate está posto para a sociedade como um todo, como alerta Lemgruber: 
Revista NEP, Núcleo de Estudos Paranaenses, Curitiba, v.4, n.2, dez. 2018

Quem paga impostos neste país precisa entender que, por trás de tudo isto, está uma política de combate à criminalidade equivocada, que aposta no endurecimento da legislação penal como instrumento para garantir a nossa segurança e que tem despejado nas cadeias, com extrema rapidez, um número de presos muito superior àquele que o Sistema de Justiça Criminal consegue digerir e colocar de volta na rua (LEMGRUBER, 2001, p. 29).

Sobre o propósito de sua obra Prisões da Miséria e publicações subsequentes sobre o tema, Wacquant esclarece que objetiva:

uma análise descontinuísta e difusionista que rastreie a circulação de discursos, normas e políticas punitivas elaboradas nos Estados Unidos como ingredientes constitutivos do governo neoliberal da desigualdade social e da marginalidade urbana" (WACQUANT, 2012, p. 13).

Tal objetivo nos instiga a ir além do que foi, de modo preliminar, analisado neste artigo e se coloca o desafio de perceber a conexão apontada por Wacquant por diferentes caminhos.

É possível compreender a penalidade neoliberal a partir da discussão da ampliação da legislação penal bem como da adoção de legislações similares às já adotadas por outros países ou ainda do debate social acerca de questões como a pena de morte ou a redução da maioridade penal. Ou seja, devemos buscar novas perspectivas que ampliem e qualifiquem a discussão da globalização da penalidade neoliberal.

\section{Referências}

CAMPBELL, John L. Neoliberalism's penal and debtor states. A rejoinder to Loïc Wacquant. Theoretical Criminology. Califórnia: V. 14, n.1, 2010, p. 59-73. Disponível em: 〈https://goo.gl/5aTLRZ>. Acesso em: 23/10/2018.

COELHO, Edmundo. A Criminalização da Marginalidade e a Marginalização da Criminalidade. In: A oficina do Diabo e outros estudos sobre criminalidade. Rio de Janeiro: Record, 2005. p. 255-287.

DEPEN. Departamento Penitenciário Nacional. Levantamento Nacional de Informações Penitenciárias. Brasília: 2017. Disponível em: 〈http://portal.mj.gov.br/depen/〉. Acesso em: 23/10/2018. 
Revista NEP, Núcleo de Estudos Paranaenses, Curitiba, v.4, n.2, dez. 2018

HALLSWORH, Simon e LEA, John. Reconnecting the king with his head: The fall and the resurrection of the state in criminological theory. Crime Media Culture. Terre Haute: 2012, n.8, p. 185-195. Disponível em: 〈https://goo.gl/8Vpi8e>. Acesso em: 23/10/2018.

ICPS. Internacional Centre of Prison Studies. World Brief. [online]: 2012. Disponível: em: <www.prisonstudies.org>. Acesso em: 23/10/2018.

LEMGRUBER, Julita. Controle da criminalidade: mitos e fatos. Revista Think Tank. São Paulo: n. 15, 2001, p. 1-29. Encarte. Disponível em: 〈https://goo.gl/7sfenG >. Acesso em: 23/10/2018.

MANHATTAN INSTITUTE. Portal do Manhattan Institute for Policy Research. Disponível em: 〈http://www.manhattan-institute.org>. Acesso em: 23/10/2018.

MINISTÉRIO DA JUSTIÇA. Sistema Penitenciário no Brasil. Dados Consolidados. Brasília: Ministério da Justiça, 2008. Disponível em: 〈http://portal.mj.gov.br/depen/>. Acesso em: 23/10/2018.

MINISTÉRIO DA JUSTIÇA. Espaços Urbanos Seguros: ORIENTAÇÕES GERAIS. Brasília: Ministério da Justiça, 2009.

MINISTÉRIO DO ESPORTE. Pintando a liberdade Pintando a Cidadania. Brasília: Ministério da Justiça, 2009.

WACQUANT, Loïc. As prisões da miséria. Rio de Janeiro: Zahar, 2001.

Os condenados da cidade: estudo sobre marginalidade avançada. Rio de Janeiro: REVAN, 2001a.

Punir os pobres: a nova gestão da miséria nos Estados Unidos. Rio de Janeiro: REVAN, 2007.

A tempestade global da lei e ordem: sobre punição e neoliberalismo. Revista de Sociologia e Política. Curitiba: v. 20, n. 41, p. 7-20, fev. 2012.

WASLEY, Roy. World Prison Population List (second edition). Londres: Great Britain Home Office Research Development and Statistics Directorate, 2000. Disponível em: <https://goo.gl/uvvHCA >. Acesso em: 23/10/2018.

World Prison Population List (ninth edition). Londres: Internacional Centre for Prison Studies, 2010. Disponível em: 〈https://goo.gl/1ZLi54〉. Acesso em: 23/10/2018.

Recebido: 10 set. 2018

Aceito: 16 nov. 2018 
NE P Revista NEP, Núcleo de Estudos Paranaenses, Curitiba, v.4, n.2, dez. 2018 